\title{
Central Hyperthermia Due to Intracerebral Hemorrhage Treated with Baclofen: A Case Report
}

\author{
Jiyong Iruon Park, Sung-Kyun Hwang \\ Department of Neurosurgery, Ewha Womans University Mokdong Hospital, Ewha Womans University College of Medicine, \\ Seoul, Republic of Korea
}

Corresponding author:

Sung-Kyun Hwang

Department of Neurosurgery, Ewha Womans

University Mokdong Hospital, Ewha Womans

University College of Medicine, 1071,

Anyangcheon-ro, Yangcheon-gu, Seoul 07985,

Republic of Korea

Tel: $+82-2-2650-2872$

Fax: +82-2-2650-0948

E-mail: nshsg@ewha.ac.kr

Received: July 6, 2021

Revised: August 30, 2021

Accepted: September 2, 2021

\begin{abstract}
We report the treatment of a rare case of central hyperthermia due to intracerebral hemorrhage $(\mathrm{ICH})$ in the basal ganglia with baclofen. Central hyperthermia is associated with a high mortality rate and poor prognosis among patients with failure of the thermoregulation system. A 35-year-old man arrived at the emergency room with the sudden loss of consciousness and right-sided hemiparesis. Computed tomography revealed an ICH in the left basal ganglia with a midline shift. Following craniotomy and evacuation of the $\mathrm{ICH}$, the patient developed persistent hyperthermia. Laboratory investigations for fever did not aid in determining the origin, and the fever did not respond to any antibiotics or antipyretics. Oral baclofen was started at a dose of $30 \mathrm{mg} /$ day, which was increased to $90 \mathrm{mg} /$ day. The patient's temperature markedly decreased to the normal range. Baclofen can be considered for treating suspected central hyperthermia in patients with $\mathrm{ICH}$.
\end{abstract}

Key Words: Baclofen; Basal ganglia; Cerebral hemorrhage; Hyperthermia, induced

\section{INTRODUCTION}

Central hyperthermia is defined as high body temperature usually caused by stroke, and it responds poorly to antipyretic treatments. Prolonged central hyperthermia that develops from stroke is associated with a high risk of morbidity and mortality ${ }^{2,4,6,10,16-18)}$. We report a rare but successful case of management of a patient with central hyperthermia, which occurred after intracerebral hemorrhage $(\mathrm{ICH})$ in the basal ganglia with baclofen.

\section{CASE REPORT}

A 35-year-old man with no medical history presented to the emergency room with sudden loss of consciousness (Glasgow Coma Scale, EIVIM4) and right-sided hemiplegia on neurologic examination.
Non-contrast computed tomography (CT) demonstrated acute left basal ganglia hemorrhage with a midline shift (Fig. A). The patient was treated with emergency decompressive craniectomy and hematoma evacuation (Fig. B). Post surgery, he was admitted to the intensive care unit and managed with mechanical ventilation with monitoring systems and medication. On postoperative day (POD) 12, he presented with intermittent fever and sudden muscle rigidity. Despite thorough diagnostic evaluation to rule out the focus of infection and full coverage of broad-spectrum antibiotics, the fever persisted and fluctuated in the range of $38.2^{\circ} \mathrm{C}$ to $39.6^{\circ} \mathrm{C}$. Routine biochemistry and hematological tests showed no evidence of inflammation with a normal white blood cell count $(7,900 / \mathrm{mL})$, C-reactive protein level $(5.3 \mathrm{mg} / \mathrm{L})$, and negative blood culture results. The anticoagulation tests and lumbar puncture cerebrospinal fluid analysis on POD 16 were normal (red blood cells, $220 / \mathrm{mm}^{3}$; white blood cells, 5/mm ; glucose, $71 \mathrm{mg} / \mathrm{dL}$; and protein, $51 \mathrm{mg} / \mathrm{dL}$ ). He showed no signs of active inflammation, and his coagulation test results
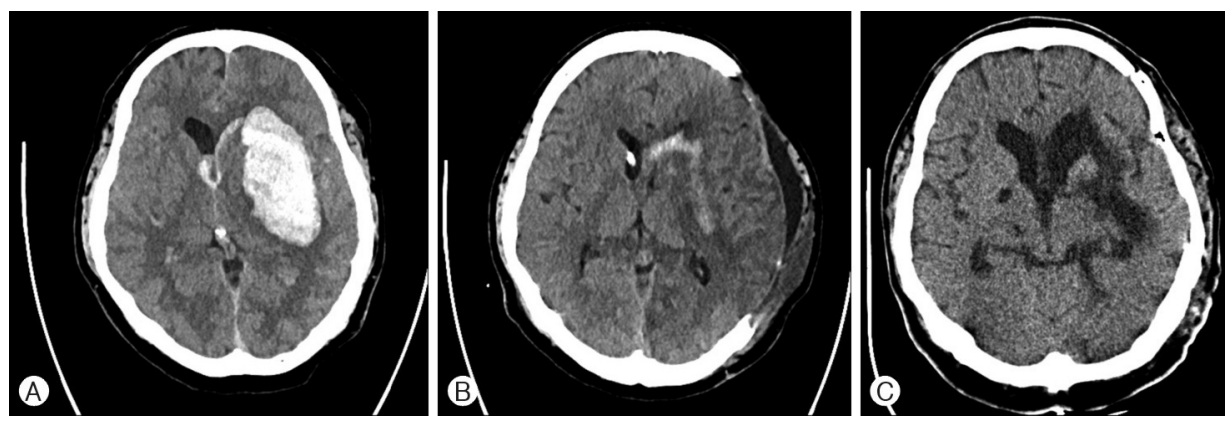

Fig. 1. (A) Computed tomography axial image demonstrating intracerebral hemorrhage $(\mathrm{ICH})$ in the left side basal ganglia with a midline shift. (B) Extensive left frontoparietal craniectomy with resolving state of $\mathrm{ICH}$. (C) Cranioplasty with scanty subdural fluid collection. 


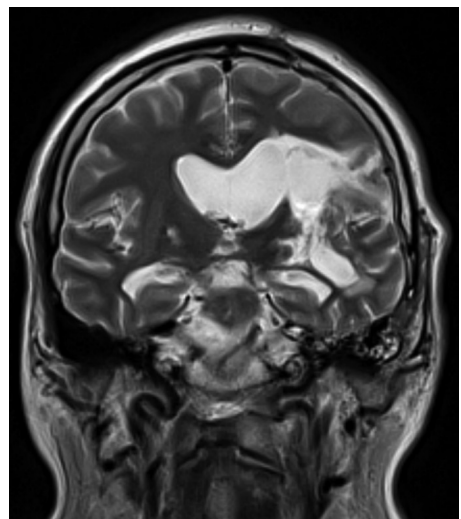

Fig. 2. Magnetic resonance imaging demonstrated that encephalomalacia due to intracerebral hemorrhage in left frontotemporoparietal lobe, basal ganglia, extemal capsule.

were normal; therefore, it could be conduded that central hyperthermia was the likely cause of the prolonged fever. Central hyperthermia was treated with baclofen at a dose of $30 \mathrm{mg} /$ day on POD 18, and the dose was increased to $60 \mathrm{mg} /$ day on POD 22 . Hyperthermia did not subside when the dose of baclofen was $30 \mathrm{mg} / \mathrm{day}$; however, the body temperature fluctuated between $39^{\circ} \mathrm{C}$ and $37^{\circ} \mathrm{C}$ on POD 23 but did not reach the normal level. On POD 30, we increased the baclofen dose to $90 \mathrm{mg} /$ day, and the body temperature was reduced to normal levels. The neurological state showed gradual improvement with a reduction in stupor and muscle rigidity. Postoperative $\mathrm{CT}$ demonstrated resolved $\mathrm{ICH}$ without any midline shift (Fig. 1C). Postoperative magnetic resonance imaging demonstrated encephalomalacia due to $\mathrm{ICH}$ in the left frontotemporoparietal lobe, basal ganglia, external capsule (Fig. 2).

\section{DISCUSSION}

Central hyperthermia is characterized by a cytokine-related elevation setting of the thermoregulatory center that fails to respond to antipyretic treatments. The diagnostic criteria for central fever are not standardized and there are different opinions regarding the time of fever onset, but we used the following criteria to diagnose central hyperthermia: (1) no prior infection or fever for at least one week before onset of stroke; (2) presence of fever $\left(\geq 38.3^{\circ} \mathrm{C}\right)$ after onset of stroke; and (3) negative workup for infection-originated fever ${ }^{5,7,9)}$. Early diagnosis and treatment of central hyperthermia are crucial. However, in most cases, early diagnosis is difficult because of the time-consuming tests required to rule out infection. Furthermore, the mortality rate is high because of complications related to high fever, including sudden cardiac arrest, rhabdomyolysis, and acute renal failure ${ }^{9)}$. The precise mechanism of central fever in stroke remains unknown. Body temperature is strictly controlled in the human body. Multiple physiological mechanisms are involved in thermoregulation, all coordinated with the cutaneous thermal receptors, spinal cord, midbrain, and thermoregulatory center of the hypothalamus ${ }^{13)}$. Several possible mechanisms can explain central hyperthermia. First, the central pathway controls thermoregulatory thermogenesis and innervation of the brown adipose tissue (BAT). The BAT is an essential effector organ for nonshivering heat generation that helps maintains euthermia during exposure to cold ${ }^{19}$. Preoptic chiasma and anterior hypothalamic nuclei are the centers of thermoregulation. Lowering the temperature of these areas activates the BAT, while raising the temperature deactivates the BAT and nonshivering thermogenesis ${ }^{11,15}$. Preoptic chiasma/anterior hypothalamic nuclei generate efferent signals that reach the ventromedial hypothalamic nuclei and act as $\gamma$-aminobutyric acid (GABA) inhibitors $^{12)}$. Signals from the ventromedial hypothalamic nucleus reach the raphe nuclei through the lower midbrain, releasing GABA from this region ${ }^{14}$. The thermore- gulatory signal is connected to the sympathetic chain, and the nons- hivering thermogenesis in the BAT is controlled by the sympathetic chain ${ }^{7,9}$. Second, dysfunction of the serotonergic or dopaminergic system can also be a possible cause of central hyperthermia; the serotonergic system is associated with heat generation, while the dopaminergic system is associated with autonomic and endocrine regulation ${ }^{18)}$. Symptoms of central hyperthermia are thought to be related to dopamine or serotonin syndrome, including hyperthermia, altered mental state, muscle hypertonia, and autonomic dysfunction. These symptoms are similar to those of our patient who had hyperthermia, altered mental state, and muscle hypertonia. Lastly, the correlation of the central fever with the $\mathrm{ICH}$ volume and third ventricular shift suggests possible hypothalamic compression after ICH. Previous studies found no significant correlation between the $\mathrm{ICH}$ location and development of central hyperthermia, although thalamic and basal ganglia involvement showed a trend towards being more common in patients with central hyperthermia ${ }^{4,6}$.

The precise mechanism of action of baclofen is not fully known; however, thus far, baclofen is an agonist of the beta subunit of GABA receptors on mono- and polysynaptic neurons at the level of the spinal cord and brain ${ }^{1)}$. Regarding the antipyrefic effect, we hypothesized two mechanisms of action by which baclofen possible lowered the body temperature. First, baclofen, a GABA receptor agonist, replaces GABA, thereby directly inhibiting the raphe nuclei and suppressing BAT activation, while GABA is blocked because of the mass effect of $\mathrm{ICH}^{7}$. Baclofen lowers the body temperature by affecting the dopaminergic system. According to a previous study, low concentrations of baclofen caused increased activity of dopaminergic neurons in rodent ventral tegmental area slices ${ }^{3)}$. As the symptoms of our patient were related to dopamine deficiency, baclofen's action of increasing the activity of dopaminergic neurons may lower the body temperature of the patient. However, this hypothesis can be controversial because, in this study, higher doses of baclofen inhibited dopaminergic neurons, which usually raises the body temperature, but our patient's body temperature decreased as the dose of baclofen was increased.

\section{CONCLUSION}

This case provides guidance for understanding the thermoregulation dysfunction in patients with ICH. Thus, in condusion, persistent central hyperthermia should be considered as a possible cause of fever in patients with $\mathrm{ICH}$, and baclofen administration should be considered 
as a treatment option.

\section{CONFLICTS OF INTEREST}

No potential conflict of interest relevant to this article was reported.

\section{REFERENCES}

1. Albright AL: Baclofen in the treatment of cerebral palsy. J Child Neurol 11:77-83, 1996

2. Badjatia N: Hyperthermia and fever control in brain injury. Crit Care Med 37:S250-S257, 2009

3. Cruz HG, Ivanova T, Lunn ML, Stoffel M, Slesinger PA, Lüscher C: Bi-directional effects of $\mathrm{GABA}(\mathrm{B})$ receptor agonists on the mesolimbic dopamine system. Nat Neurosci 7:153-159, 2004

4. Deogaonkar A, De Georgia M, Bae C, Abou-Chebl A, Andrefsky $\mathrm{J}$ : Fever is associated with third ventricular shift after intracerebral hemorrhage: pathophysiologic implications. Neurol India 53: 202-207, 2005

5. Hocker SE, Tian L, Li G, Steckelberg JM, Mandrekar JN, Rabinstein AA: Indicators of central fever in the neurologic intensive care unit. JAMA Neurol 70:1499-1504, 2013

6. Honig A, Michael S, Eliahou R, Leker RR: Central fever in patients with spontaneous intracerebral hemorrhage: predicting factors and impact on outcome. BMC Neurol 15:6, 2015

7. Huang YS, Hsiao MC, Lee M, Huang YC, Lee JD: Baclofen successfully abolished prolonged central hyperthermia in a patient with basilar artery occlusion. Acta Neurol Taiwan 18: 118-122, 2009

8. Kilpatrick MM, Lowry DW, Firlik AD, Yonas H, Marion DW: Hyperthermia in the neurosurgical intensive care unit. Neurosurgery 47:850-856, 2000
9. Lee HC, Kim JM, Lim JK, Jo YS, Kim SK: Central hyperthermia treated with baclofen for patient with pontine hemorrhage. Ann Rehabil Med 38:269-272, 2014

10. Mendieta Zerón H, Arriaga García Rendon JC: Remission of central fever with morphine post traumatic brain injury. J Med Liban 62:57-61, 2014

11. Mohammed M, Madden CJ, Burchiel KJ, Morrison SF: Preoptic area cooling increases the sympathetic outflow to brown adipose tissue and brown adipose tissue thermogenesis. Am J Physiol Regul Integr Comp Physiol 315:R609-R618, 2018

12. Morrison SF, Madden CJ, Tupone D: Central neural regulation of brown adipose tissue thermogenesis and energy expenditure. Cell Metab 19:741-756, 2014

13. Morrison SF, Nakamura K: Central neural pathways for thermoregulation. Front Biosci (Landmark Ed) 16:74-104, 2011

14. Morrison SF, Sved AF, Passerin AM: GABA-mediated inhibition of raphe pallidus neurons regulates sympathetic outflow to brown adipose tissue. Am J Physiol 276:R290-R297, 1999

15. Nakamura K, Morrison SF: A thermosensory pathway mediating heat-defense responses. Proc Natl Acad Sci USA 107:88488853, 2010

16. Schwarz S, Häfner K, Aschoff A, Schwab S: Incidence and prognostic significance of fever following intracerebral hemorrhage. Neurology 54:354-361, 2000

17. Shibata M: Hyperthermia in brain hemorrhage. Med Hypotheses 50:185-190, 1998

18. Sung CY, Lee TH, Chu NS: Central hyperthermia in acute stroke. Eur Neurol 62:86-92, 2009

19. van Marken Lichtenbelt WD, Schrauwen P, van De Kerckhove S, Westerterp-Plantenga MS: Individual variation in body temperature and energy expenditure in response to mild cold. Am J Physiol Endocrinol Metab 282:E1077-E1083, 2002 